\title{
A NOTE ON FIGURES
}

\section{$\mathcal{P}$}

In preparing the figures for this book, I have not always used images from the earliest edition of a particular text. Sometimes a later edition provided a better image for reproduction; sometimes obtaining a particular image from the earliest text was too difficult. In every case, however, I have checked the earliest available edition against the figure reproduced. In Sources and Credits, therefore, I have provided bibliographical information for the image reproduced and the date of the earliest edition consulted. Spelling of titles has not been modernized. In most cases I have cited the text from which an image is taken rather than the artist or engraver. 
$\mathcal{B}_{\text {ut the common form-with necks-was }}$ a proper figure, making our last bed like our first; nor much unlike the urns of our nativity, while we lay in the nether part of the earth, and inward vault of our microcosm.

Sir Thomas Browne, Hydriotaphia

\footnotetext{
$q_{\text {n }}$

ndividualism, at first, only saps the virtues of public life; but in the long run it attacks and destroys all others and is at length absorbed in downright selfishness.
}

Alexis de Tocqueville, Democracy in America 
FETAL POSITIONS 
